Philosophy and Progress: Vols. LVII-LVIII, January-June, July-December, 2015 ISSN 1607-2278 (Print), DOI : http://dx.doi.org/10.3329/pp.v57il-2.3120l

\section{A MIRROR UP TO NATURE: IS PHILOSOPHY REALLY A FORM OF POETRY?}

\section{Michael McGhee*}

'Thou shouldst not have been old before thou hadst been wise'

I

In the midst of philosophical activity we can lose our sense of philosophy. In this loss of perspective favour one set of aptitudes and interests at the expense of others.

It may not seem so to sceptical outsiders-and it is ironic that the philosophers have for so long been a fitting topic for satire-but there is a diversity of interest, aptitude and sensibility within the philosophical community and a corresponding diversity of perspectives which taken alone and excluding integration with others become narrow tunnels of vision.

\footnotetext{
* Honorary Senior Fellow, Department of Philosophy, University of Liverpool, E-mail : Mcghee@liverpool.ac.uk
}

When they are put on the defensive by these same sceptical outsiders philosophers will re-iterate the Platonic thought that the unexamined life is not worth living, and assert when required that philosophy is the discipline by which that examination is conducted. But this is often a smokescreen, behind which philosophy remains absorbed in a conversation with itself, in a competitive, not to say neurotic refinement of the terms of the elenchus, with little regard for the life that waits patiently to be examined. The criticism has been, in other words, that philosophy has lost its way. This caricature has as they say the advantage of throwing prominent features into relief even as they exaggerate them.

Philosophy is supposed to (re-)examine itself from time to time, and is prompted to do this when a sense emerges that something is lacking or amiss. This cannot happen, though, if the terms of reflection on its own activity - and this is the danger of reflection - pleasingly reduplicate the terms of the activity and allow us comfortably to re-endorse them.

But that there is something unsatisfactory about the state of philosophy is almost a commonplace now among those who stand outside the mainstream. So, what is it to be a philosopher at all? I shall try here to advance a claim that is by no means original: a conception of philosophy as a moral endeavour with an emancipatory intent.

\section{II}

There are two aspects to this intent, just as there are two aspects to emancipation, what one is liberated from and what one is liberated for, and this distinction corresponds to that between the critical and the creative aspects of the philosophical dialectic. It is unfortunate, however, that the critical aspect - the elenchus - has in practice almost eclipsed 
the other, and that the role of the elenchus has been almost lost sight of by those caught up in a self-proliferating analysis of its terms.

For most of us the process of asking questions, of analysis and argument for and against a position, almost defines philosophy, it is what we do. Its role is essential, but it is one of negative critique, which is not to condemn it as destructive, though I have heard people express bitterness about the casual destruction of their beliefs by someone cleverer or more experienced than themselves. The point of the elenchus lies in the uncovering and dismantling of the confusions and errors that prevent us from seeing the truth, and it is destructive only when it is cut off from the other, creative aspect of philosophy - a good teacher can, after all, use the creative tension of aporia to liberating effect.

But now, the elenchus does not deal well with inattention, with ungrounded, undisciplined, distracted forms of attention - which demand a training which would be available only in an ideal philosophical community. It is, of course, something we neglect - we see ourselves as engaged in an analytical and forensic task and that doesn't include a strategy for distracted and absorbed attention.

Consider the prisoners in the Cave, for instance, who have no reason to believe that they are prisoners, and there is nothing in their experience, apparently, that tells for or against such a claim - we know they are looking in the wrong direction and are too absorbed in what they are doing to turn around. There is nothing in their experience that tells for or against the claim that they are prisoners but, on the other hand, though most of them are ignorant of their position, we can imagine that some of them are also deluded: they have a view about their experience, viz that it encompasses reality.
The prisoners, though, are an image of ourselves and, although it may seem that we have no reason to believe that they reflect our own condition, the possibilities of its application are evident-we can at least think that we once were or that others are.

What interests me about the liberated prisoner is not their onward and upward path to the noonday sun-it is their discovery of a perspective which allows them to see the whole scene, to see for the first time the mechanisms which had previously determined the form of their experience, the scope of their vision, the focus of their attention. Their release allows them, in other words, to stand in a place from which they can see the limits and the conditions of an earlier perspective.

The dialectic in its elenchic aspect seeks to dispel illusion and mere appearance, and it is destructive or even wanton if it fails to fulfil its role of clearing the way to wisdom and virtue-but it does not, as I said, include a strategy for inattention, except of course that in its other, creative aspect philosophical dialectic does have a strategy, as we have just seen. It holds a mirror up to nature, offers images that show us our condition from a point of view we are uneasily half aware of. It holds a mirror up to nature, but a particular mirror, it offers images that reproach and challenge consoling or pleasing self-images that simply reflect the terms of our absorption. The significance of the philosophical or genuinely creative metaphor is that it embodies an idea or estimate of what it represents. The consoling or flattering self-image is a form of self-authentication, reflecting back not the form of our desire but its object as perceived under the sway of that desire, whereas the philosophical metaphor is creative just to the extent that it implicitly queries what it represents, carries a perspective on it, an idea of it-it is not a replication of the terms of the perspective it represents, but sees it as a 
conditioned whole from a position beyond it. In the third Critique Kant makes the distinction between talent and genius reside in the latter's power to awaken ideas and, as it were, to see (human) nature as phenomenon in the light of those ideas. In Kantian terms, the philosophical metaphor awakens an idea-not, to use one of his examples, an enticing image of fame or celebrity, say, that reflects its glamour as an object of desire, but leads us to see it clearly and see it whole.

\section{III}

A starlit or a moonlit dome disdains

\section{All that man is}

All mere complexities

The fury and the mire of human veins ${ }^{l}$

Our attention is distracted from the fury and the mire of human veins when it is caught by the beauty of the moonlit dome - an aesthetic moment in which our immersion is suspended - a dome which, in its contrasting magnificence, casts a critical light, or allows us to cast a critical eye on what we were immersed in, from a point beyond it. Attention to this reflected light upon the cathedral dome leads us towards its source, which is itself a form of reflected light, and so on, in a graduated progress, not unlike that of the liberated prisoner, in which a perspective emerges upon human nature that waits to be incorporated into a larger conception that depends upon an embodiment through the ordeal of purification.

The elenchus is only a part of the dialectic, a necessary set of tasks which can be destructive if it fails to fulfil its role of clearing the way to wisdom and virtue. The terms 'confusion', 'error', 'appearance', 'illusion', are forensic terms that refer us

\footnotetext{
${ }^{1}$ W B Yeats, Byzantium
}

to states of the human subject-from whom the truth is concealed. And the traditional, critical function of the elenchus then makes way for a second, creative function-disclosure, revelation, unconcealment of what is unacknowledged by or hidden from the subject thus compromised.

Diagnosis and cure are both parts of the philosophical enterprise, but they express a human concern that explains the freed prisoner's return to the cave. The disquieting thought is that the freed prisoner is an image of homo philosophicus - one whose passion for wisdom is a passion to become wise but also a passion for wisdom to prevail.

In Plato's Symposium the philosopher is symbolised by Eros but part of the discussion of eros is juxtaposed to a discussion of poiesis and we need, I think, to look at both of these notions to draw some conclusions about what it is to be a philosopher at all.

However, that eros and poiesis work together will start to become evident if we look at a third aspect of the discipline, viz, the creative act by which the community of philosophers is brought into and then sustained in being in the first place-viz, the foundation of the Academy. The creative necessity for this foundation is expressed obliquely in the dialogue essay, and it comes in the description of the ascent of eros:

The next stage is for him to reckon beauty of soul more valuable than beauty of body; the result will be that, when he encounters a virtuous soul in a body which has little of the bloom of beauty, he will be content to love and cherish it and to bring forth such notions as may serve to make young people better; in this way he will be compelled to contemplate beauty as it exists in activities and institutions, and to recognise that here too all beauty is akin ... (210c) 
Why will he be 'compelled'? Because the forms of activity and of what we institute as a practice provide the conditions under which beauty of soul may flourish.

\section{IV}

In his Notebooks Wittgenstein wrote:

Philosophie dïrfte man eigentlich nur dichten ${ }^{2}$

And the young John Stuart Mill wrote in a letter to Thomas Carlyle that

... one thing not useless to do would be to ... make those who are not poets understand that poetry is higher than logic, and that the union of the two is philosophy. ${ }^{3}$

Mill's suggestion that philosophy is a union of logic and poetry might be compared with Descartes' remark to Princess Elizabeth, that the human being is a union of soul and body, une seule personne, as he puts it, not a soul within a body. Philosophy, on this view, would have its own integrity as an art-form, and the 'poetry' would be integrated into the form of interrogative and discursive dialogue. Nevertheless, to think of philosophy as a distinctive art form we shall need to think of it as at least sharing some of the characteristics of poetry, see it, in other words, as a related form of poiesis, a form of creativity.

If these remarks and those preceding it put pressure on our conception of philosophy-and our view in consequence of the current condition of the discipline-they also put pressure on our conception of poetry-in either case the pressure takes the form of the charge that we have allowed a dichotomy to arise

\footnotetext{
2 'Philosophy ought really to be written only as poetic composition'

${ }^{3}$ Cited in Reeves, Richard, 2007, p 68
}

where there ought to be a union, and if we need to reassess our conception of philosophy we also need to reassess our conception of poetry, or at least reflect on what it might be to think of philosophy as in some significant sense 'poetic'. We have a dichotomy, an intellectual distortion that nevertheless determines in advance the direction of conscious reflection, when two elements that belong together within an integrated whole, are cut in two and treated independently and out of all connection with one another. Overcoming the dichotomy is a matter of restoring the connections and finding a way back to the sense of an integrated whole. If in Mill's terms philosophy without poetry is reduced to logic it is tempting to identify logic with the critical, elenchic function and poetry with the creative and revelatory. But what essential characteristic of poetry is being invoked, and what is the nature of the convergence? To explore this further we shall need to look at Diotima's remarks about the nature of poiesis as the creative activity of bringing into existence something that did not previously exist-and in the case of philosophy I should want to say that it takes the form of bringing into existence a form of self-understanding that was not previously there, one that constitutes a transformation of subjectivity, so that something new is brought into being.

In any event poetry must be more than 'the merely decorative word', as Pound once said,- - not 'what oft was thought' but rather what we are by its means only now able to bring to thought at all, showing us what we had previously been unaware of, making new sense-in the spirit of Shelley's 'marking the before unapprehended relations of things'which poetry does, he says, just because it is 'vitally metaphorical'. This is the function that poetry shares with philosophy, or, rather, contributes to the properly integrated discipline of philosophy. But we need an account of its 
revelatory function that comes within the scope of the emancipatory intent. The form of the philosophical metaphor is, as we have already seen, one that reveals the possibility of inhabiting a perspective upon the world as a limited whole-to give us the sense of a universe as Paul Valery put it, but to see it from a position beyond it - to form an estimate of (human) nature as phenomenon that informs and enhances that nature. This philosophical intent is available widely in literature of course, as when Dennis Potter, for instance, seduces us into a state of desire as we gaze at some scene, only to confront us with its vicious nature, in a way and with a force that depend upon the success of the seduction.

We should understand metaphor here, not as an ornamental way of expressing what we already know, but as an access to understanding, a means of disclosing, not an item of knowledge, but a world. It might be helpful here to reassert the point that we should not think in terms of a category of 'metaphorical meaning' but think of metaphor rather as a function of language that depends upon literal meaning to bring about what has been called a burgeoning of meaning. Thus, to use the example famously discussed by Stanley Cavell, 'Juliet is the sun' does not, bizarrely, describe the girl, making a 'wildly false' statement about her, but rather reveals to Romeo a source of possible descriptions, not, again, of the girl, but of the form of his relationship to her, which can then be unfolded in a series of comparisons. In fact this free-standing metaphor has the form of an identity statement. The identity statement is the metaphor, and it depends for its effect upon the literal use of the terms that compose it, and just because of that it produces a degree of conceptual shock: we are forced by our own recoil to ask ourselves how it could possibly be true.

Gerard Manley Hopkins does something similar when he tells us that 'the mind has mountains', etc, where the metaphor is unfolded in the poem itself. The series of illuminating comparisons are not, however, between the mind and mountains, but the mentality of grief and despair is compared to the weariness and the danger, the terror and vertigo confronted by a climber. And you need to have hung there. Here again, the form of the experience of mental life coalesces and is seen, brought into focus, where before it was simply endured, in a way that may remind us of Spinoza's discussion of the conditions under which an affect that is experienced as passio comes to be experienced as actio as we form a clear and distinct idea of it.

But the pressure towards metaphor comes from the painful inarticulacy that precedes insight, where it is no clarity about what is to be articulated. The creator of the metaphor, who seeks to communicate the form of an experience with which they are coming to grips, is not in any great degree different from the recipient. The appropriateness of the comparisons is registered unconsciously and in advance, we see ahead of conscious recognition. The interesting metaphors are precisely those in which there is unconscious recognition that one thing, whose nature has been unclear to us, is like another whose nature is clear to us. The recipient of the metaphor is also brought under the same conceptual pressure. But how remarkable, that features of the natural world, the sun shining, for example, should be available for comparisons that illuminate the form of our own human life, and that our attention can be focused on things external because we have already started to see in them an isomorphism with things internal.

\section{V}

In the Symposium Plato famously presents us with a metaphor which succeeds at once in representing the form of life of the 
philosopher and at the same time makes that life the figure of a human subjectivity whose character is illuminated by that metaphor. So, Eros is the figure of the philosopher who is the figure of the human being in process of becoming. Both Socrates and Alcibiades count as philosophers, in the sense that they both desire wisdom, though of course Alcibiades is presented as someone who thinks of wisdom as something that he can have as a possession, and is thus shown not to understand the nature of what he desires.

Now Diotima declares, somewhat disingenuously, that:

The truth is that we isolate a particular kind of eros and appropriate for it the name of eros which really belongs to a wider whole, while we employ a different name for the other kinds of eros.

She makes similar remark a few moments later about poiesis: we assign exclusively to verse the name of 'poiesis' or poetry, even though there are other activities that are equally 'poetic' in their creatively bringing into existence what did not previously exist.

I say 'disingenuous' because the cases are somewhat different-poiesis is a generic term for creative activity and it is clear enough that the various arts can be assembled under that heading-anything that brings something into being that was not there before is a form of poiesis, though the kind that interests Diotima is that which brings into being wisdom and virtue-which would make the poetry she cites as exemplars of this-Homer and Hesiod-philosophical poets. As philosophers we have been trained to make distinctions and to look for difference under the appearance of identity, but sometimes it is important to see identity under the appearance of difference and whereas that is straightforward in the case of poiesis, it requires creative and imaginative thought to follow
Diotima in her account of eros-which is just what metaphor demands. What is striking, indeed, is that it is by reference to the language of desire and procreation that we have to understand philosophy as a form of poiesis-since the bringing into existence that constitutes it a form of poiesis, indeed the bringing into existence in terms of which we have established a conception of creative life at all, is through the metaphorics of conception, gestation and bringing forth, not to mention Socratic midwifery. And then of course there is begetting, which tends to be prioritised by the male Platonic psyche.

If a metaphor begins with what is familiar to us-in this case, the experience of sexual life and desire, of being an erastes and an eromenos - it does so because what is familiar provides a transferable structure that sheds light on an area of experience that is less familiar. That would be mysterious, were it not that our attention is already drawn to something familiar because we have started to discern, although dimly, its isomorphism with what we are struggling to understand, our attraction to the image is the beginning of coming to grasp what remains unfamiliar-we make progress in understanding through metaphor, it is the medium of unconscious discernment-we already know that it carries across. The essence of Diotima's claim is that eros provides us with a philosophical metaphor for what it is to be a human being at all, as represented by the philosopher-it gives us a perspective on a form of life.

There is plenty of irony here- a form of experience can be familiar without being well understood, and what Plato offers us is a metaphor from sexual life whose applications allow us then to turn round as it were and locate and shed light on the experience of sexual life itself. But the metaphor is about the process of self-understanding, and it serves to bring that process into focus. Eros or Love is not a beautiful god but 
is exemplified in the figure of one who is 'weather-beaten, shoeless and homeless'. This is generally taken to be a figure of Socrates himself, the philosopher/erastes, but it works in part because it is recognisable as a figure of sexual desire seeking its unattained eromenos whom, as Diotima insists, it does not properly seek to possess but with whom rather it seeks to procreate, so that what issues from the union is wisdom and virtue.

The salient feature of desire is the suffered lack or absence of its object. I find it hard to understand the idea of a desire for wisdom, though, except as a response to or as an aspect of a distressed, negative experience of its absence-whether one thinks of those who wish that they themselves were or had been wiser or less foolish, or those who see the ghastly consequences of human folly more generally and wish that wisdom might prevail. The distressed state is one which forces the question, how then should we live, if not like this? If this is the essential condition of philosophy then the philosopher is someone who confesses to an unsatisfactory condition of subjectivity and conduct.

\section{VI}

I have already echoed Kant in seeing the philosophical metaphor as one by which we gain a perspective upon a world, upon a totality or limited whole, and I mention this again now because in talking about wisdom and its contrast, therefore, with folly, we enter a crucial and contested area. If we contrast wisdom with folly or foolishness we must contend with a contrast between 'worldly' wisdom and what 'the world' counts as folly as well as a notion of wisdom for which worldly wisdom is a form of folly. If I express myself here in terms that derive from the Christian New Testament they also reflect the contrast between the cynicism of Glaucon and Adeimantus and the Socratic diagnosis of their attitudes as reflecting a sickness within the soul. This takes us back to the liberated prisoner and the claim I made at the beginning that philosophy is a moral endeavour with an emancipatory intent since the world of the prisoners is precisely 'the world' in this sense and the freed prisoner regards it from a position that transcends it.

Diotima tells us that the gods and the ignorant have something in common-neither desire wisdom, the gods because they are already wise and the ignorant because they do not know they lack it. Those who do desire wisdom, on the other hand, are in between these conditions: they fall between wisdom and ignorance, not entirely ignorant because they know they lack wisdom-because, as I have suggested, they suffer from its absence. It is this existential plight that gives the idea of a passion for wisdom its force, a force analogous and related to the passion for justice.

\section{Diotima says}

Wisdom is one of the most beautiful things and Eros is the love of beauty, so it follows that Eros must be the love of wisdom and consequently in a state half way between wisdom and ignorance.

But really we need a better objective correlative than this to render intelligible the unkempt figure of Socrates as the representation of that desire. 'Wisdom is one of the most beautiful things' does not give us what we need to capture the ordeal of the erastes, does not give us a clear sense of the spur that impels the philosopher forward suffering from the failure to attain it.

If we need a distinction between knowledge and wisdom we need to specify a difference. The difference lies in the fact that wisdom is a condition in which one not only knows how 
things are as opposed, for instance, to how they had seemed to be, but in which we comport ourselves and order our desires in the light of that knowledge: this is the condition of sophrosune and the intermediate state between ignorance and wisdom, the uneasy space between bad faith and acknowledgment, is the crossing line between akrasia and enkrateia, and one main way of lacking wisdom and feeling and thus suffering the lack is in this experience of dissonance between what one knows and how one acts, where the desired unity between them defines the unity of being found in the sophron.

\section{VII}

I said at the beginning that the released prisoner sees the mechanisms that had determined the form of his earlier experience, sees them from a position beyond them, and this of course is the crux of the problem of communication, as we shall see. But one should also recall the moment in the narrative when it is suggested that the other prisoners would surely think that the freed prisoner was mad, and would want to kill him, wouldn't they?-a suggestion which Glaucon incautiously endorses, taking on the role of Plato's ideal audience. His response is significant as a form of recognition. He endorses a violence of reaction that makes psychological sense only as an expression of mauvaise foi. It isn't in fact the prisoners who declare that they would indeed want to kill him: surely they are too engulfed in their ignorance to be capable of such a response. But Glaucon's agreement shows how an audience already and uneasily applies the image to themselves, expressing the resentful half-acknowledgement that it tells a truth about them.

But the image also helps us to track the distinction between being genuinely wise and 'the wisdom of this world' since this fits the picture of a perspectivally-challenged judgment on the part of the prisoners. They also represent a picture of absorption or self-enclosure which cannot see beyond the horizon of self-regarding desires. To talk about 'the world' in this sense, or to talk about 'worldly wisdom' not only marks its epistemological scope as narrower than, as an enclosure within, a larger 'reality' but implies an ethical criticism of the nature of that enclosure. 'This world' is precisely a function of reality mediated by self-regarding concerns, which is one way of making sense of the ideas that the prisoners see shadows and not substance.

Now the main difficulty with talking of 'the world' in this way is that there is no shortage of traditions that populate and offer precise delineations of what lies beyond it. Plato's liberated prisoner is set up to leave the cave and then return, stumbling back in to announce his discoveries. But any proffered description of the world beyond the cave will suffer systematic distortion by his audience, who will interpret it in the light of their own experience and desires, whereas of course it is partly intended as an implicit critique of the form of that experience.

But the liberated prisoner should not be offering such descriptions at all, should not be offering descriptions of the landscape that lies beyond the confines of the prisoners' position. He should rather be offering descriptions of the prisoners. It is only when they are able to free themselves from their bonds that they can start to look around and make their own journey onwards and upwards. This is the point of holding a mirror up to nature and the need for satire, since folly is highly recognisable even if wisdom is not. The liberated prisoner can comment on the prisoners and their conduct-or rather, the philosopher can comment on the human beings whose condition is represented by the story and very regularly shared by themselves. Their more ample and encompassing 
perspective is shown in their attitude to the other prisoners and, if we revert to the early books of the Republic, what Socrates casts his gaze upon and sees as a sickness of the soul is rampant injustice. What is manifest but not necessarily apparent in the demeanour of the liberated prisoner is the compassion that derives from a perspective that cannot otherwise be shared.

If we start talking about what 'lies beyond' the world, it looks as though we are talking about a supersensible and noumenal realm. It is true that I instinctively shrink from such notions and probably need to defend that instinct, but in the meantime we can think it as an ethical distinction. In certain contexts, to talk about 'the world' or 'this world' or 'worldly' is just to refer to the absorbed condition of the prisoners, and the position beyond it is an ethical position. The expression 'the world' is a term of moral critique as well as a term of epistemology, and refers to an enclosure within reality that is mediated by absorption in shadows. Nevertheless we can still think the idea of a transformation or conversion in which the world is 'redeemed' or purified of the egocentric self-enclosure and acquisitive tendencies whose disastrous consequences are now endangering future generations. But in that case we shall still need to mark a distinction between the world and what lies beyond the world. But again it would be a mistake to think that what lies beyond the world, whether purged or unpurged, is reality. It is rather that what lies beyond the world is such reality as we have not so far encompassed and it lies open before us if we had a mind to look. Perhaps this is what Guenther meant when he referred to 'the open dimension of being'. However, in order to look we need aesthetic or meditative experience, where thought, in whatever terms, is suspended, allowing us look at things for the first time and see further relations of things not yet apprehended.
There is something about this in Rilke's eighth Duino Elegy which bears a striking resemblance to the image of the cave. Animals provide for him an image of those who are aware of what he calls das Offene. It is only our eyes that are turned away-the animals seem to look through us to something beyond that we cannot see. The child is constantly pulled back and made to look at what is already established. There are six references in the short elegy to our being turned in the wrong direction:

\section{Always world \\ And never Nowhere without not}

He thinks we see das Offene only as we approach death, which is when we start to look beyond it:

We are always turned towards creation, and so

See there only a reflection of freedom

Obscured by ourselves

\section{VIII}

Finally, I want to return to something I mentioned near the beginning. I had made the remark that there is a creative as well as a critical aspect to philosophy, but also that the formation of the Academy was a creative act that sought to protect the conditions for the possibility of the philosophical relationship.

It is tempting here, is it not, to burst into satirical song about how the instrumentalism and the managerial ethos of our Higher Education Institutions, the demand to demonstrate research excellence, to deliver demonstrable benefits to the economy, society, public policy, culture and quality of life, all tend to undermine the telos of the academy as a place in which the philosophical relationship can be embodied in practice and 
in which its members can flourish. The dissonance is harsh and grating. However, I have it in mind to end with a well known remark of Alasdair MacIntyre:

What matters at this stage is the construction of local forms of community within which civility and the intellectual and moral life can be sustained through the new dark ages which are already upon us.

It may be that Plato's academy rather than his republic provides the exemplar for such associations because it is dedicated to the release of prisoners.

\section{References}

1. MacIntyre, A. (2007). After Virtue: A Study in Moral Theory. London: Duckworth

2. Plato. (1951). The Symposium (trans. Hamilton, W.). Harmondsworth: Penguin

3. Reeves, R. (2007). John Stuart Mill: Victorian Firebrand. London: Atlantic Books

4. Rilke, R.M. (1939). Duino Elegies (trans. Leishman, J.B. \& Spender, S.). London: Chatto \& Windus

5. Wittgenstein, L. (1980). Culture and Value (trans. Winch, P.). Oxford: Basil Blackwell 